\title{
METRÓPOLE E INFORMAÇÃO: A RADIODIFUSÃO NA REGIÃO DO RECIFE
}

\author{
Cristiano Nunes Alves ${ }^{1}$
}

\begin{abstract}
Resumo: Refletimos sobre os nexos entre o uso do território e a variável informacional na metrópole, analisando a radiodifusão na Região do Recife. Abordamos o escopo da densidade normativa embutida no sistema de concessões de rádio no Brasil e expomos os contornos da radiodifusão do Recife em sua relação com os grandes grupos de informação. Em seguida indagamo-nos sobre o critério musical rádio recifense, para então analisar a situação em torno das rádios livres (não concessionadas) e comunitárias. Buscamos contribuir para a discussão sobre as possibilidades de se adensar a circulação de espessuras informacionais ascendentes no território.
\end{abstract}

Palavras-chave: Metrópole; Informação; Radiodifusão; Recife; Uso do território

\section{METROPOLIS AND INFORMATION: BROADCASTING IN THE REGION OF RECIFE}

\begin{abstract}
We reflect on the connections between use of territory and informational variable in the metropolis, analyzing broadcasting in the Region of Recife. We approach the scope of the built-in normative density in the radio concession system in Brazil and expose the contours of the broadcasting of Recife in their relationship with large groups of information. Then we asked ourselves about the musical criterion radio Recife, and analyze the situation around free radio (no concession) and community. We seek to contribute to the discussion on the possibilities to thicken the circulation of ascending information in the territory.
\end{abstract}

Key-words: Metropolis; Information; Broadcasting; Recife; Use of territory

\section{METRÓPOLE E INFORMACIÓN: LA RADIODIFUSIÓN EN LA REGIÓN DE RECIFE}

Resumen: Meditamos sobre los nexos entre el uso del territorio y la variable informacional en la metrópoli, analizando la radiodifusión en la Región de Recife. Abordamos el alcance de la densidad normativa embutida en el sistema de concesiones de radio en Brasil y exponemos los contornos de la radiodifusión de Recife en su relación con los grandes grupos de información. En seguida nos indagamos sobre el criterio musical em la radio recifense, para entonces analizar la situación en torno a las radios libres (no concesionadas) y comunitarias. Buscamos contribuir a la discusión sobre las posibilidades de adensar la circulación de información ascendente en el territorio.

Palabras clave: Metrópoli; Información; Radiodifusión; Recife; Uso del territorio.

\footnotetext{
${ }^{1}$ Professor adjunto do Departamento de História e Geografia/CECEN da Universidade Estadual do Maranhão. Email: cris7cris7@yahoo.com.br
} 


\section{INTRODUÇÃO}

Metrópole marcada pelo imbricamento entre distintas classes sociais, o Recife ${ }^{2}$, capital do Estado de Pernambuco, importante elo informacional fora da Região Concentrada (Santos \& Silveira, 2001) ${ }^{3}$ é o abrigo de um vigoroso circuito de produção musical e fonográfica, caracterizado pela diversidade cultural, mas que, todavia pouco é difundido pelo circuito de radiodifusão local.

Tal fato somado à densa presença da radiodifusão no Recife, assim como nas grandes cidades brasileiras, nos faz indagar o quão eficaz é a "catequese musical e sonora" contemporânea orquestrada pelos grandes grupos de informação. Sobretudo nessas aglomerações urbanas o circuito de radiodifusão, e a produção de informações que lhe é vinculada em torno de um "repertório médio" (musical ou noticioso), demonstram o seu poder, determinando o conteúdo recebido pelo ouvinte.

Apesar do recente espraiamento da internet e das possibilidades de divulgação intrínsecas a esse veículo, os grandes meios de informação de massa, como o rádio, permanecem sendo as mais eficientes conexões midiáticas com as grandes massas urbanas, influenciando decisivamente na opinião pública e na formação do gosto.

Na elaboração do presente estudo, além do levantamento bibliográfico e documental sobre a temática, presente, entre outros, em livros, e na análise da produção informacional embutida, foram fundamentais os trabalhos de campo e a reunião de informações primárias, estas aparecendo no texto, acompanhadas de um asterisco*. Nessa via, em Recife entrevistamos locutores de rádio, músicos, militantes informacionais, produtores musicais, entre outros agentes, bem como realizamos visitas técnicas a locais como emissoras de rádio (concessionadas ou não), estúdios fonográficos ou órgãos do poder público ligados à esfera cultural.

Tendo como fio condutor uma reflexão sobre a metrópole e o componente informacional, se organiza o presente artigo do seguinte modo: em um primeiro momento apresentamos uma problematização da questão do uso do território, da radiodifusão e da

\footnotetext{
${ }^{2}$ Com 1.599 .514 habitantes (IBGE, Estimativa 2013) e composta por 94 bairros, a cidade do Recife integra a Região Metropolitana do Recife (RMR) formada por catorze cidades.

${ }^{3}$ Santos \& Silveira (2001) propõem uma regionalização para o Brasil baseando-se da difusão desigual das variáveis do período atual. Os autores supracitados afiançam a existência da Região Concentrada, composta pelo centro-sul do país, o sul e o sudeste, contiguidades que em comum têm o fato de concentrar redes e sistemas técnicos instrumentais a difusão técnica-informacional, condição e resultado de uma grande densidade de fluxos, sejam estes de pessoas, capitais, informações ou mercadorias.
} 
densidade informacional. Em seguida, abordamos o escopo da densidade normativa embutida no sistema de concessões de rádio no Brasil, para então expormos os contornos dos circuitos de radiodifusão da Região do Recife em sua relação com os grandes grupos de informação atuantes na metrópole pernambucana.

Em um quarto momento destacamos as iniciativas que apontam para a adoção de um critério musical no circuito de rádio FM do Recife: haveria lugar para uma produção fonográfica diversificada e/ou lugarizada?

Por fim, debruçamos-nos sobre a situação em torno das rádios livres (não concessionadas) e comunitárias, indagando-nos sobre as possibilidades de adensar a circulação de espessuras informacionais ascendentes no território por meio desses veículos.

Com a proposta de esmiuçar a um só tempo radiodifusão e o movimento do território, visamos melhor compreender a situação concreta resultante do processo de espacialização de normas, materialidades, ações e formas, que a partir dos usos mediados pela técnica, configuram o espaço geográfico e os seus lugares no Recife.

\section{PROBLEMATIZANDO A QUESTÃO: METRÓPOLE, USO DO TERRITÓRIO E DENSIDADE INFORMACIONAL}

Premissa cara ao estudo do Recife, concordamos com Santos (1991) Silveira (2011) quando estes autores consideram a grande cidade, a metrópole, o mais complexo espaço constituinte do conjunto de lugares onde a história de produz, chamado de território usado, logo, rica empiria ao desenvolvimento da reflexão sobre as possibilidades de comunicação no período atual:

A metrópole revela mais claramente diversos usos em cooperação e concorrência. Reunindo todas as divisões territoriais do trabalho, os capitais, as tecnologias, as formas organizacionais, os consumos, os produtos e os valores, a metrópole é o espaço banal por excelência... (Silveira, 2011, p. 37)

De acordo com Santos (1991, p. 149), por meio de fluxos informacionais, a metrópole se sobressai na tarefa de chegar a outra cidade, pois "nenhuma dispõe da mesma quantidade e qualidade de informações que a metrópole.”

Segundo Santos (1997, p. 232): "A utilização do território pelo povo cria o espaço" produção unificada de duas demandas: a tecnosfera, a dimensão da materialidade, do mundo físico e dos objetos, em geral associada à demandas externas ao lugares e a psicosfera, a 
dimensão imaterial, dos fluxos informacionais, da ideias, crenças, paixões e ideologias, lugar da criação de valores e hábitos.

Lançando mão da noção de uso do território, busca-se assim, erigir pontes entre a teoria e a concretude de objetos e ações, o empírico em suas contradições, possibilidades e lutas políticas (Ribeiro, 2003), focando a análise do território visto como "um todo complexo onde se tece uma trama de relações complementares e conflitantes” (Santos et al., 2000, p. 3).

Malgrado o poder desigual de cada um de seus agentes, o território usado "um quadro de vida" (Silveira, 2011, p. 35), abriga a todos, e, guarda a marca de seu tempo. A esse respeito, lembra Santos (1994: 115), devemos ter "consciência da época em que vivemos" marcada pelo crescente papel da informação, tornada força motriz, "variável chave" configurando o período do meio-técnico-científico-informacional.

Essa técnica da informação característica do meio contemporâneo traz consigo inúmeros aspectos correlatos, tais qual a informatização, a creditização, a instantaneidade ou a importância do controle informacional, permitindo-nos pensar que:

O espaço geográfico e o sistema urbano como o esqueleto produtivo da nação são altamente hierarquizados por fluxos de informação superpostos a fluxos de matéria não propriamente hierarquizantes (Santos, 1994, p. 119).

Nesse viés, Silva (2011) afirma que o território usado seria ele próprio o meiotécnico-científico-informacional, pautado na violência do dinheiro e da informação, e que "em contextos metropolitanos, adquire importância e vitalidade em consequência da profusão e, sobretudo, da porfia de seus usos" um movimento de modernização que "nega a história das pessoas comuns" (Silva, 2011, p. 159).

Em nossa abordagem sobre a metrópole do Recife destacamos a densidade informacional gerada em torno da radiodifusão. De acordo com Santos (1999; 1997) o acontecer dos lugares pode ser estudado a partir dos elementos relacionados à espessura dos contatos e transmissões de informação. Para Santos (1997) a densidade informacional, em larga medida decorrente da densidade técnica, diz respeito ao lugar em suas relações alhures, suas articulações e contatos com outros lugares.

Manifesta em formas particulares como propaganda, difusão de notícias ou publicidade, a profusão de fluxos informacionais por meio da indústria cultural (Adorno 2004 [1947]) tolhe as possibilidades comunicacionais do cotidiano dos lugares:

Esse vivido individual da vida cotidiana separada fica sem linguagem, sem conceito, sem acesso crítico ao seu próprio passado, não registrado em lugar algum. Ele não se comunica. (Debord, 1997 [1977], p. 107). 
A informação, variável circulante compõe-se na difusão, processo espacial (Hägerstrand, 1952, 1967) envolvendo o modo como os aspectos de uma nova cultura se espraiam. Não por acaso, o circuito de rádio concessionado é um retrato do modo como os grandes grupos de informação produzem hierarquicamente uma série de escalas e usam o território. Por outro lado, espessuras indicando a produção de "informações geograficamente orgânicas” (Silva, 2005, p. 4) parecem se sobressair por meio da ação de rádios livres ou comunitárias. Eis a situação a ser investigada a seguir.

\section{O CIRCUITO DE RADIODIFUSÃO INSTITUIIDO NO RECIFE: PARA A AÇÃO DOS GRANDES GRUPOS DE INFORMAÇÃO}

O sistema federal de concessões de rádio se baseia em classes de potências, normas definidoras das escalas geográficas de abrangência dos sinais radiofônicos (Tabela 1). Em teoria o alcance das emissoras FM pode variar de uma raio de $1 \mathrm{~km}$ (caso das emissoras comunitárias), até cerca de $80 \mathrm{kms}$.

\section{Tabela 1}

\begin{tabular}{|c|c|c|c|}
\hline \multicolumn{4}{|c|}{ O circuito de FM, técnica e norma: o sistema de concessões e as escalas geográficas } \\
\hline \multicolumn{2}{|c|}{ Densidade normativa } & \multicolumn{2}{|c|}{ Densidade técnica } \\
\hline Categoria & Classe & Potência (Watts) & $\begin{array}{c}\text { Abrangência teórica } \\
(\mathbf{k m s})\end{array}$ \\
\hline \multicolumn{2}{|c|}{ Comunitária } & 25 & 1 \\
\hline \multirow{3}{*}{ Local } & $\mathbf{C}$ & 300 & 7 \\
\hline & B 2 & 1.000 & 12 \\
\hline & B 1 & 3.000 & 16 \\
\hline \multirow{7}{*}{ Regional } & A 4 & 5.000 & 24 \\
\hline & A 3 & 15.000 & 31 \\
\hline & A 2 & 30.000 & 36 \\
\hline & A 1 & 50.000 & 40 \\
\hline & E 3 & 60.000 & 54 \\
\hline & E 2 & 75.000 & 66 \\
\hline & E 1 & 100.000 & 78 \\
\hline
\end{tabular}

Elaboração própria, 2014. Fonte: informações da ANATEL.

Entretanto, a abrangência teórica para cada uma das classes potência pode variar de acordo com uma série de aspectos, tais qual a estrutura da emissora, qualidade de seu sistema de transmissão, localização de sua torre irradiadora, entre outros. Em suma: densidade técnica-informacional e aspectos políticos têm uma íntima relação com o raio de alcance de uma determinada emissora.

Temos então uma abrangência teórica e uma abrangência real, correspondente à área 
receptora de um determinado sinal até o local onde este começa a falhar. Desse modo, observam-se áreas de sinal fraco para determinadas emissões, bem como áreas nas quais um canal pode ter interferência mútua com outro canal, de mesma frequência, porém oriundo de outro local.

Com relação ao circuito FM do Recife, o dial (conjunto de sinais de rádio FM recebidos a partir do Recife) é composto por 31 emissoras. Vinte desses veículos são responsáveis por transmitirem conteúdo musical brega/popularesco (12 rádios) e religioso (oito rádios), enquanto as músicas de elevador ${ }^{4}$, o conteúdo musical eclético e o conteúdo educativo são difundidos por duas rádios cada.

Desse conjunto de emissoras, 13 delas são concessões do Recife, 11 são de outras cidades da RMR e 7 são concessões de cidades pernambucanas situadas fora da RMR (Figura 1). O contraponto entre a profundidade e o amplo alcance dos sinais de rádio difundidos pelas rádios comerciais e os sinais difundidos pelas rádios comunitárias, estes de curto alcance, dános ideia do quão discrepantes são as espessuras informacionais engendradas por cada um desses tipos de emissoras.

No controle desses meios de informação se confundem três tipos de agentes: políticos, organizações religiosas (Igreja Batista, Igreja Internacional da Graça, Igreja Universal do Reino de Deus, entre outros) e grandes grupos de informação (Rede Globo, Rede Jovem Pan, Grupo João Santos, entre outros). Do total desses agentes controladores das emissoras, 14 deles têm sede na RMR, metade desses oriundos da cidade do Recife.

A situação em torno do Circuito AM (amplitude modulada) não é muito diferente: com os mesmos tipos de agentes controladores, das 16 emissoras componentes do circuito, 9 delas transmitem conteúdo religioso, 2 emissoras respondem por um conteúdo musical popularesco, outras 4 mesclam jornalismo e um conteúdo musical eclético em sua programação, enquanto uma emissora é especializada em jornalismo.

No circuito AM, 10 emissoras têm origem na RMR, seis delas oriundas do Recife; por sua vez, temos Alagoas, Paraíba e outras cidades de Pernambuco, fora da RMR, cada uma dessas áreas, abrigando duas emissoras.

Dois aspectos se destacam em nossa análise sobre a dinâmica em torno da radiodifusão e a produção musical do Recife:

1) De modo recorrente, a internet é citada no meio acadêmico e fora dele como a saída para o círculo fechado de influências, timbres, ritmos e sons determinados pela grande mídia

\footnotetext{
${ }^{4}$ Algo próximo do chamado Muzak, os sons de fundo. Mais informações consultar Schafer (1997).
} 
massiva. Mesmo que a internet tenha auxiliado a divulgação da produção fonográfica, afiançam nossos interlocutores*, a radiodifusão ainda tem um papel chave no processo de criação de um público em torno de um determinado artista, e as demandas correlatas a esse processo, como o adensamento do circuito de shows.

2) Fato consensual apurado em nosso campo de informação primária, tem-se que o circuito de rádio do Recife, praticamente não divulga a produção fonográfica local e quando o faz se restringe aos gêneros popularescos, alicerçados num repertório médio. Mesmo a Cena Manguebit ${ }^{5}$, que logrou grande repercussão no Brasil e fora dele, jamais teve espaço no circuito de rádio recifense.

\footnotetext{
${ }^{5}$ Com suas músicas e um release tornado manifesto redigido por Fred 04, chamado "Caranguejos com Cérebro" lançado em 1992, deram os contornos do que seria a Cena Manguebit, grupos como Mundo Livre S/A, Chico Science \& Nação Zumbi ou Mestre Ambrósio. Tais agentes contribuem decisivamente para a difusão de um olhar especial sobre a cultura do Recife e de Pernambuco. Mais informações em Teles (2000).
} 


\section{Figura 1}
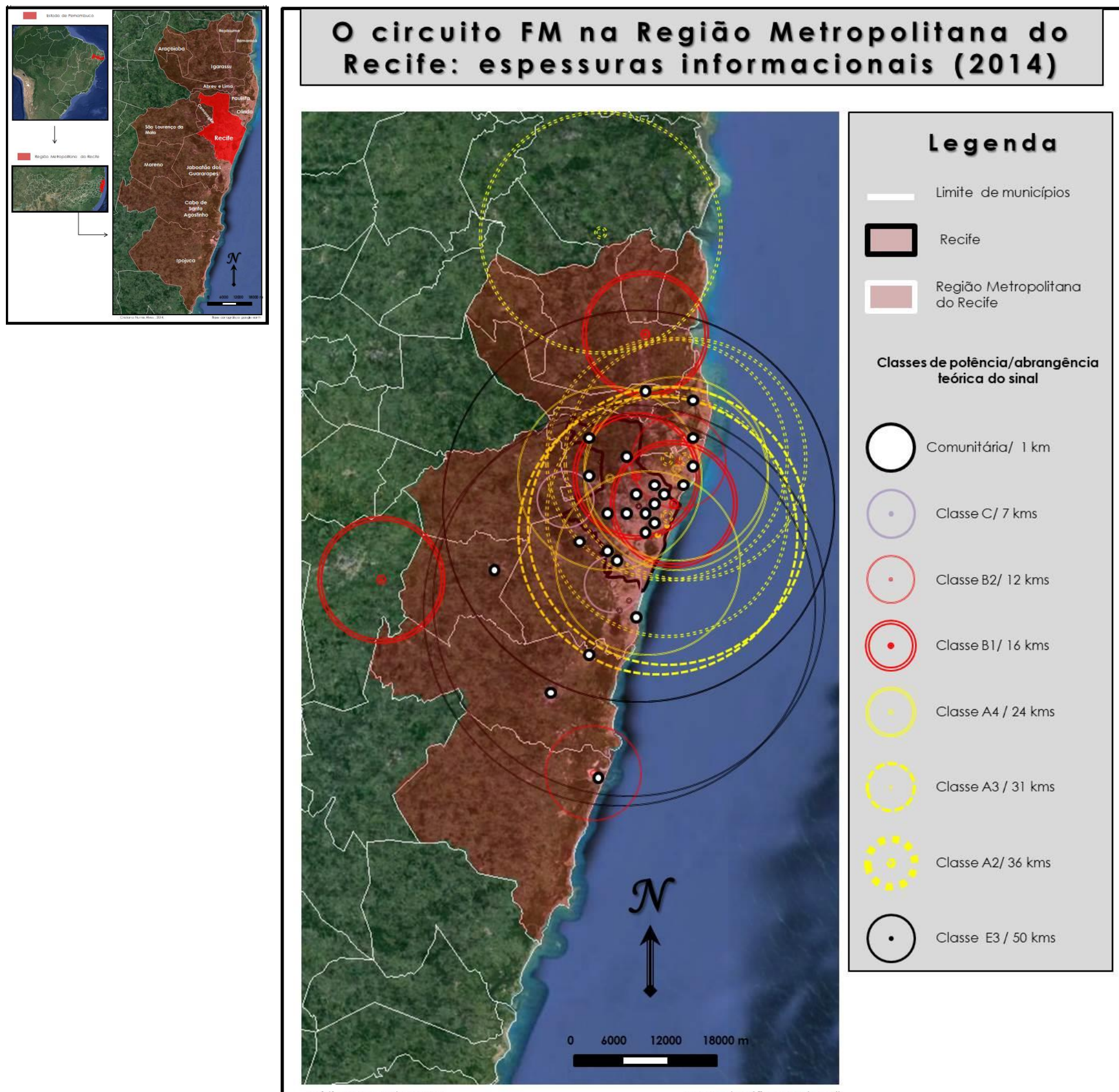

O produtor do Estúdio fonográfico Muzak (Casa Forte Recife), Marcelo*, pondera a respeito da relação entre internet e rádio como meios da difusão da produção fonográfica "Com internet o pessoal tem conseguido escoar muito a produção (...) agora, evidentemente que o rádio tem um peso muito grande.” Por sua vez, Paulo André Pires *, dirigente de 
produtora Astronave ${ }^{6}$ (Boa Vista, Recife), entende que mesmo com a internet, meios de informação como o rádio e a TV permanecem preponderantes para atingir as grandes aglomerações humanas e divulgar o produto artístico ou não:

Eu acho que independentemente da internet pra você chegar numa comunidade como Rio Doce (Olinda) e no grande Brasil como ele é, no povão, só tem um caminho que é a grande mídia. Se não for a mídia é a igreja ou alguma coisa do tipo.

Sobre o tema, o jornalista e escritor José Teles* enfatiza a relação entre a difusão musical no rádio e o impulso para a realização de eventos musicais, considerado por ele o verdadeiro motor do circuito sonoro recifense: "não tocou em rádio não adianta... é a rádio que leva o povo para o show" a questão é que o circuito de rádio, completa o jornalista, está "totalmente imbecilizado."

João Florentino*, diretor chefe da Rede Estação de radiodifusão, e antigo proprietário da extinta rede de lojas de discos Aki Discos ${ }^{7}$, chama atenção para a aposta das emissoras de rádio apenas nos sucessos não admitindo riscos: "A rádio não quer correr riscos, de tocar o novo em função do IBOPE, então ela só toca o que já e sucesso, ai fica difícil do cara fazer sucesso."

Por sua vez, para o articulador cultural, apresentador e locutor de rádio, Roger de

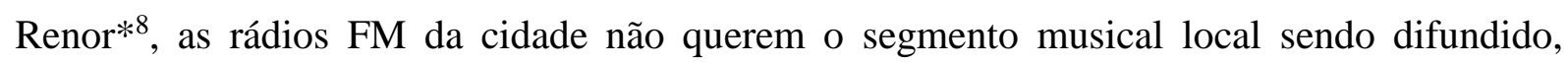
alegando se tratar de uma produção musical impopular, muito "cabeça". Roger assevera* que a estratégia dos detentores dessas emissoras no Recife, passa por inventar "uma porra dumas bandas de brega que nem são o brega real, que nem são o brega popular que já rola espontaneamente"

Parte dessa estratégia, e seguindo um procedimento que parece marcar o circuito de rádio em todo o país, a FM em Recife, desde o seu período tenro nos anos 1980, funciona mediante o pagamento jabá ${ }^{9}$ e a manipulação das paradas de sucesso. A esse respeito o líder da banda Mundo Livre S/A, Fred 04*, vocalista da banda Mundo Livres S/A e figura central de Cena Manguebit recorda a sua experiência trabalhando no final dos anos 1980 na

\footnotetext{
${ }^{6}$ Idealizador do Festival Abril Pro Rock, evento artístico surgido no Recife no ano de 1993, hoje consolidado no calendário nacional de festivais.

${ }^{7}$ João Florentino* conta que no início dos anos 1970 no Recife fundou com Djalma Figueroa, a Aki Discos, que viria a se tornar a maior rede de lojas de discos do Brasil composta por 170 lojas em meados dos anos 1980. Em seu auge, a atuação da Rede ultrapassava o território nacional, comercializando discos ainda em países da Europa, sobretudo em Portugal, e da América Latina.

${ }^{8}$ Ex-proprietário da "Soparia" do Pina, um dos locais essenciais para se entender a ebulição da cena manguebit no início dos anos 1990.

${ }^{9}$ Propina recebida pelas emissoras de rádio como condição para difusão de um determinado produto musical.
} 
Transamérica, uma das rádios FM pioneiras do Recife, afirmando que as paradas musicais eram e continuam sendo totalmente manipuladas, e de modo algum refletem os interesses dos ouvintes:

"Tinha o papo de que a rádio toca o que o povo quer. Era tudo fraudado, era tudo jabá, era tudo manipulado (...) eu mesmo teve uma época que quando eu era estagiário da Transamérica, eu ficava ali ouvindo pedido da galera e eu sabia que aqueles pedidos ali, nenhum iria entrar... Só se tivesse a ver com a gravadora mesmo, já tivesse a ver com o playlist $^{10}$ (...) Podia ser mil (pedidos) por dia, mas não entrava, e se a música não estourasse saia da programação.”

Tais procedimentos se inserem num escopo maior das emissoras de FM, constituído por interesses dos grandes grupos de informações detentores desses veículos em sua relação com agentes da indústria do disco, empresários e produtores do setor de entretenimento. Trata-se de uma operação intensa, presente em um sem número de lugares na Região: desde a programação de rádios e televisores, passando por cartazes e outdoors.

No Recife predominam dois grandes grupos de informação: o Grupo Diário Associados e o Sistema Jornal do Commercio de Comunicação. Eficientes ferramentas político-econômicas, tais grupos constituem-se por diversas mídias em sinergia: emissoras de rádio e TV, jornais impressos e digitais, e extrapolam suas ações para outros ramos, caso do Sistema Jornal e as suas atividades no mercado imobiliário e na administração de shopping centers.

A criação de modismos por meio da injunção de um repertório médio é apenas parte das diversas facetas vívidas na utilização do rádio como um instrumento ideológico, criado de uma psicosfera (Santos, 1997) dócil para com o poder instituído. Daí lembrarmos-nos do depoimento de Roger de Renor* remetendo-se a uma conversa que teve com o proprietário de uma das concessões de rádio do Recife, onde este afirmou querer o canal de rádio para fazer campanha contra o então governador de Pernambuco.

No mesmo sentido, o músico Fred $04 *$ indagado a respeito de sua experiência no poder público, entre os anos de 2010 e 2011 como assessor do então secretário de cultura Renato L, destacou o choque de interesses entre a mídia local e os agentes do circuito sonoro preocupados em difundir uma produção diversa da veiculada pelos meios de informação de massa já consolidados no Recife: "Não foi surpresa, apenas uma confirmação, chocante e cruel do quanto a mídia local é uma guerra política, não existe impressa livre.” Fred 04*

\footnotetext{
${ }^{10}$ Conjunto de músicas que compõem a programação de uma determinada emissora.
} 
completa a sua afirmação se remetendo a letra da música "Por Pouco", lançada em 2004 pelo seu grupo, o Mundo Livre S/A:

“Contribuintes não contam

Torturadores não sentem

Esculturas de lama não morrem Jornalistas mortos não mentem.”

Vê-se como a música local se torna um mero detalhe num grande jogo de interesses envolvendo redes de poder político e o controle do território usado por grandes empresas como um todo.

\section{EM BUSCA DO CRITÉRIO MUSICAL NA RADIODIFUSÃO RECIFENSE: ALTERNATIVAS PARA A PRODUÇÃO FONOGRÁFICA LOCAL?}

Como se observa, a grande força de difusão do circuito sonoro em Pernambuco gira em torno dos segmentos do brega, do pagode e do forró. Ou seja: os sons alternativos estética e politicamente, que contribuíram para difundir alhures o nome do Recife e de Pernambuco, enquanto lugares onde a diversidade cultural se fazem presente, não têm audiência junto ao grande público de Pernambuco ${ }^{11}$, devido, em especial, à sua pouca difusão nos meios de massa locais e a dependência que se instalou em relação aos mecanismos de incentivo cultural do poder público. Nesse viés, declara Roger* de Renor:

“Caruaru não escuta a música que se faz no Recife... é mais fácil tocar em São Paulo, Rio de Janeiro, Europa do que tocar em Caruaru, ou Gravatá (...). Não tem um circuito dentro do estado sem ser algo vinculado ao governo"

Em busca de indícios da adoção de critério musicais na programação do circuito de rádio FM no Recife, ressalta-se que para nossos interlocutores* apenas a Rádio Universitária FM e a Rádio OI FM se caracterizam por darem espaço em sua programação para a produção fonográfica local e/ou alternativa ao repertório médio.

\footnotetext{
${ }^{11}$ Não obstante o monopólio dos meios de informação e o máximo controle do conteúdo a ser exibido, lembra Roger de Renor* "a gente cria um mercado", algo que poderia ganhar um maior alcance caso houvesse um mínimo de verdade e mesmo visão de mercado por parte dos dirigentes das rádios e televisões atuantes no Recife. Daí dirigente do festival e produtora cultural Recbeat (Boa Vista, Recife), Gutie* destacar a formação limitada do profissional de rádio: "não existe a capacidade de entender que ele (o profissional do rádio) pode abrir outras frentes pra rádio dele...”
} 
Com operações encerradas no início de 2012 a Rádio OI FM ${ }^{12}$, segundo Fred 04*, por ter um patrocínio regular, não recebia jabá difundindo uma produção alternativa, atraindo os interessados por música na cidade.

Por sua vez, o produtor do Selo (gravadora) Joinha, Homero* (Casa Amarela, Recife), entende que em relação aos anos 1990 hoje é possível uma maior inserção de artistas locais na programação das rádios FM do Recife. Homero* cita além da Oi FM, o contato que mantém com "Presuntinho" programador da Transamérica FM que, entre outros, veiculou na emissora o trabalho dos cantores Catarinah Dee Jah e China, ambos do Selo Joinha.

Finalmente, Marcelo*, produtor do Estúdio Muzak, assinala entre as possibilidades de abertura para uma programação diversificada e a produção musical local no circuito FM do Recife, o programa Coquetel Molotov na Rádio Universitária e o programa Toca Raul na Rádio Folha. Entretanto, sublinha o produtor*, ainda que importantes, se tratam de iniciativas muito isoladas, em horários secundários e sem conhecimento do grande público: "não são os horários quentes das rádios e a quantidade de gente que tem conhecimento desses programas ainda é pequena."

A pouca presença da produção local no circuito de rádio do Recife, implicou, entre outros, num rearranjo normativo: entrou em vigor a lei 17.861/2013, instituindo o "Momento do Frevo", por meio do qual as rádios recifenses têm que tocar duas músicas do ritmo por dia. Reportagem do portal G 1 de notícias dava conta de que um mês após a entrada em vigor da Lei, apenas a Rádio Folha a estava pondo em prática (Portal G1. Matéria de Renan Holanda, 1 de maio de 2013).

A esse termo, pauta recorrente entre nossos interlocutores* foi, sem dúvida a implantação da Rádio Frei Caneca, meio de informação que poderia dar maior visibilidade e poder de manobra pra toda uma parcela do circuito sonoro recifense e pernambucano e a propostas musicais alternativas ao repertório médio.

Informações publicadas no Jornal Diário de Pernambuco ("Rádio Frei Caneca vai operar na internet em caráter experimental", 21 de janeiro de 2014) davam conta de que a rádio Frei Caneca entraria no ar via internet antes do carnaval de 2014. Em entrevista concedida ao Jornal, o gerente de música da Fundação de Cultura Cidade do Recife (FCCR),

\footnotetext{
${ }^{12}$ As atividades da Rádio Oi FM nas sete praças onde atuava - Belo Horizonte (MG); Porto Alegre e Novo Hamburgo (RS); São Paulo, Ribeirão Preto, Sertãozinho, Campinas e Vinhedo (SP); Rio de Janeiro (RJ) e Recife (PE) - se encerraram no primeiro dia de 2012 em virtude do encerramento do contrato entre a operadora de telefonia Oi e a empresa detentora da rede, o Grupo Bel de Comunicação, com sede em Belo Horizonte. O sinal de FM foi substituído pela Rádio Verão, emissora também pertencente ao Grupo Bel e a Rádio Oi, após 8 oito anos transmitida em FM se tornou uma rádio via internet (rádio web).
} 
Patrick Torquato, explicou tratar-se de emissões experimentais, em meio a reuniões de grupos de trabalho para definir o modelo de operação da rádio. Tais reuniões seriam compostas por um grupo de agentes, entre os quais o Intervozes (coletivo de comunicação social), a EPC (Empresa Pernambuco de Comunicação) e o Núcleo de Televisão e Rádio Universitárias da UFPE.

A tentativa de implementação da Rádio Frei Caneca remonta ao ano de 1960, com o projeto de Lei Municipal 6511, que estabelecia a criação da emissora, elaborado pelo então vereador Liberato Costa Júnior (PMDB). Apenas nos anos 1990 o assunto fora retomado a partir de uma conversa entre o vereador à época Dílson Peixoto (PT) e o músico Fred 04. Nos anos 2000, durante as duas gestões do prefeito João Paulo (PT) cresceram as manifestações em prol do cumprimento do projeto, contudo a outorga definitiva da emissora seria decretada apenas em 2011, já sob a gestão do prefeito João da Costa (PT).

Mesmo com a outorga a emissora não entrou em operação ${ }^{13}$ naquele ano de 2011: o motivo alegado pelo então secretário de cultura Renato L, foi uma inadequação técnica junto ao Ministério das Comunicações. A controvérsia passa pela procura por canais de FM vagos no dial recifense, e pela localização pensada para instalação da torre de transmissão: o Alto Santa Terezinha, local que, segundo o órgão federal, poderia causar interferências em outros meio de informação da cidade (Jornal Diário de Pernambuco, 21 de janeiro de 2014).

Em meio ao impasse, da implantação da rádio Frei Caneca, esta tornou-se, inclusive, parte da plataforma dos políticos locais, caso de Geraldo Julio (PSB), prefeito eleito do Recife em 2012, que durante a sua campanha se reuniu com artistas e produtores do Recife, afirmando ser prioridade por em funcionamento a emissora (informações no sítio oficial de Geraldo Júlio na internet).

Como fazer funcionar uma emissora em Recife, uma cidade marcada pelo ecletismo de estilos e gêneros musicais? Contudo, uma posição que se mostra pertinente é o cuidado para que este veículo não se torne mais um a reproduzir o repertório médio, corolário das emissoras concessionadas por todo o país. A presença, nas discussões sobre a emissora, de empresários citados em nosso campo de informação primária* como responsáveis por trazer ao Recife artistas representantes do "mais do mesmo" imposto pelos grandes grupos de

\footnotetext{
${ }^{13}$ A primeira parte para instalação da Rádio Frei Caneca que corresponde à oficialização da outorga para transmissão já foi ultrapassada. Porém, uma série de interlocutores se mostram preocupados com a administração da Frei Caneca, entre eles, o produtor Gutie* e os músicos Dadado* (articulador cultural do Bairro de Peixinhos), Gilmar Bola 8* (músico da Nação Zumbi) e Fred 04*: "a gestão vai ser um vespeiro" prevê este último.
} 
informação, caso do produtor de eventos musicais Rogério Robalinho, nos faz destacar tal aspecto potencialmente esvaziador da proposta inicial para a emissora: um órgão que possa divulgar a produção musical pernambucana, conferindo ao ouvinte uma possibilidade de escolha.

Poder-se-ia pensar que dar conta do ecletismo sonoro de um lugar significa contemplar a todos os agentes envolvidos: mas o que dizer dos que já têm espaço cativo na grande mídia, sobretudo no circuito FM concessionado?

\section{AS RÁDIOS COMUNITÁRIAS E LIVRES: RECIFE, TERRITÓRIO NORMADO E ESPESSURAS INFORMACIONAIS ASCENDENTES}

Segundo Santos (1994, 1997), os circuitos informacionais de cima para baixo, ou descendentes, são aqueles baseados em demandas externas, por vezes criadoras de espaços rígidos, logo portadoras de lógicas e normas fundamentadas na obediência e disciplina. Estes circuitos de cima para baixo chegam aos lugares dinamizados por uma integração funcional e um maciço sistema de objetos técnicos, cuja função pode ou não ser subvertida. Por outro lado, os circuitos informacionais descendentes, ou de baixo para cima, se referem à parte dos lugares que insurge em ações lugarizadas de interesse comum, frutos de demandas comunicacionais, no cotidiano, a dimensão do espaço geográfico compartilhado.

Ainda em busca de uma análise da metrópole e indagando sobre as possibilidades de se espraiarem espessuras informacionais ascendentes por meio da radiodifusão, destacamos a seguir a situação das rádios comunitárias e livres na RMR.

- A RADIODIFUSÃO COMUNITÁRIA NA RMR: DENSIDADE NORMATIVA DESGASTADA?

O Serviço de Radiodifusão Comunitária, criado a partir da Lei 9.612, de 1998 e regulamentado via o Decreto 2.615 do mesmo ano, corresponde a emissões de 25 Watts, e cobertura de sinal restrita a $1 \mathrm{~km}$ de raio a partir da antena transmissora.

Podem requerer a outorga de uma rádio comunitária, com duração de 10 anos, renováveis (Lei 10.597 de 2002), apenas associações e fundações comunitárias sem fins lucrativos, sediadas no entorno da prestação do serviço. De acordo com o Ministério das 
Comunicações, tais emissoras podem receber uma ajuda cultural em troca da veiculação de anúncios publicitários, comprometendo-se com a difusão de uma programação diversificada e em favor dos moradores de seu entorno:

\begin{abstract}
A programação diária de uma rádio comunitária deve conter informação, lazer, manifestações culturais, artísticas, folclóricas e tudo aquilo que possa contribuir para o desenvolvimento da comunidade, sem discriminação de raça, religião, sexo, convicções político-partidárias e condições sociais. A programação deve respeitar sempre os valores éticos e sociais da pessoa e da família, prestar serviços de utilidade pública e contribuir para o aperfeiçoamento profissional nas áreas de atuação dos jornalistas e radialistas. Além disso, qualquer cidadão da comunidade beneficiada terá o direito de emitir opiniões sobre quaisquer assuntos abordados na programação da emissora, bem como manifestar ideias, propostas, sugestões, reclamações ou reivindicações." (Informações disponíveis no sítio do Ministério das Comunicações na internet).
\end{abstract}

Como pudemos observar, uma série de prerrogativas positivas para a ação das comunitárias são destacadas pelo Ministério das Comunicações, o que, para o mais desavisado, pode dar a ideia de uma situação modelo, esta dinamizada em torno das rádios comunitárias no país: a legislação e as possibilidades de ação para tais veículos.

Entretanto, os militantes das rádios livres e comunitárias* esclarecem que, apesar de existirem rádios comunitárias que realmente prestam serviços ao seu entorno, no Recife, caso, entre outros, da Rádio Dimensão, uma parcela das outorgas está a cargo de políticos e/ou igrejas, que, em virtude de suas redes de influências conseguem a liberação junto a ANATEL (Agência Nacional de Telecomunicações) com muito mais agilidade; tratam-se das rádios que reproduzem as práticas e os conteúdos difundidos pelas rádios comerciais (concessionadas).

Falamos das emissoras "pseudocomunitárias", "laranjas" ou "picaretárias" alusão ao termo picareta, que na linguagem popular designa o indivíduo ou coisa caracterizada pela má fé, o engodo e o desleixo. Nesse contexto, para o cidadão comum, sem "apadrinhamento" torna-se demasiado complicado conseguir regularizar uma emissora comunitária. Em entrevista concedida ao observatório do Direito à Comunicação no ano de 2008, a Advogada Renata Rolim lembrava que à época trabalhavam 16 pessoas responsáveis por avaliarem os pedidos de outorga no Ministério das Comunicações, na ocasião com mais de sete mil processos aguardando um parecer (Direito a comunicação, Matéria de Mariana Martins, 28 de março de 2008).

Além desses fatos, os militantes comunicacionais chamam a atenção para o raio de ação de uma emissora comunitária, de pequena amplitude mesmo para áreas urbanas, marcadas por uma maior densidade populacional, e de amplitude irrisória para áreas rurais: imaginemos o poder de ação de $1 \mathrm{~km}$ de uma rádio comunitária em localidades situadas em vastos territórios como os cerrados, os sertões ou as florestas brasileiras. 
Com outorga no estado de Pernambuco existem pouco mais de 210 rádios comunitárias (Ministério das Comunicações, 2013). De acordo com o Ministério das Comunicações, 47 rádios comunitárias operam na RMR, 35 delas se localizam em Recife e 12 são oriundas de outros municípios da Região. Obtivemos informações sobre a localização de 36 emissoras comunitárias da RMR (Figura 1)

\section{- AS EMISSORAS NÃO CONCESSIONADAS NA RMR: AS PERIFERIAS URBANAS E A BUSCA POR COMUNICAÇÃO}

Além das rádios comunitárias, em operação de acordo com Lei 9.612, atuam na RMR as rádios livres, chamadas também de alternativas, genéricas, comunitárias ou participativas, emissoras por nós denominadas "não-concessionadas"14, veículos que contestam o modelo de radiodifusão público e privado instituído.

Observamos na RMR*, uma série de emissoras não-concessionadas, prestando serviços dos mais diversos ao seu entorno, entre outros, divulgando a produção fonográfica local como no caso do rap ou dos sons tradicionais, propiciando o acesso da população a um repertório musical diversificado, alternativo ao imposto pelo circuito de emissoras concessionadas comerciais.

Com a operação dessas emissoras, questiona-se a propriedade do espectro radiofônico e todo o sistema de concessões, bem como a disparidade de potência entre uma rádio comunitária, autorizada a difundir seu conteúdo num raio máximo de 1 quilômetro e as rádios comerciais que alcançam em alguns casos, um raio de cerca de 80 quilômetros.

Segundo nosso campo de informação primária*, basicamente três problemas afligem as rádios livres: o grande número de emissoras não concessionadas a serviço de igrejas e políticos, a tentativa por parte dessas emissoras de imitar a programação das rádios comerciais e a perseguição das autoridades.

Sob esse último aspecto, o argumento mais utilizado pelos órgãos repressores para justificar as apreensões das rádios livres, é o de que tais meios de comunicação causariam

\footnotetext{
${ }^{14}$ Referimo-nos às emissoras fora do sistema de concessões conforme o Código Brasileiro de Telecomunicações (Lei 4.117 de novembro de 1962). Durante nossas pesquisas contatamos o dirigente da ABRACO de CampinasSP, Jerry Oliveira, que nos informou* os atributos necessários para que uma rádio livre cumpra as funções que dela se espera, a saber: estimular a comunicação e a participação das pessoas (ser organizativa e educativa), ser laica e apoiar a cultura popular e a diversidade.
} 
interferências, sobretudo em sistemas de aviação. Uma série de estudiosos da questão como técnicos do Centro de Pesquisa e Desenvolvimento em Telecomunicações (CPqD), afirmam tratar-se de uma falácia as possíveis interferências em sistemas informacionais de aeroportos. Entre outros, Andriotti (2004) demonstra as controvérsias em torno do tema, situação em que um discurso técnico burocrático se coloca acima de um debate a respeito da partilha dos meios de informação de massa.

No Recife, operações de apreensão, como a "Segurança no Ar", realizada em $2008^{15}$, movimentam infindáveis recursos técnicos e humanos sob a mística alegação de que o Aeroporto dos Guararapes estaria sendo atingido por emissões de rádios livres de uma série de cidades pernambucanas. Numa referência a propalada possibilidade de acidentes aéreos por conta da operação das rádios livres, os militantes do Recife*, de um modo bem humorado, enfatizaram que a única coisa derrubada pelas suas emissoras é a audiência das rádios comerciais.

Tentamos sem sucesso junto a Anatel, bem como junto ao Sistema de Informações ao Cidadão do Governo Federal, obter informações sobre as emissoras livres apreendidas no Recife. Contatamos* inclusive um dos técnicos da Regional 06 da Anatel (PE) que nos afirmou a dificuldade, mesmo para quem trabalha dentro da Agência em conseguir informações dessa natureza.

Por seu turno, os militantes comunicacionais*, afirmam que não importa o quanto persistam as apreensões, as emissoras livres continuarão em atividade. Não raro as emissoras conseguem fechar as portas e esconder os seus equipamentos antes da chegada das autoridades, isso devido a ação dos moradores do entorno, despistando a polícia e avisando os responsáveis pelas rádios, o que demonstra em larga medida uma sinergia entre o lugar e esses órgãos de comunicação.

Em busca de maiores informações sobre as rádios livres e comunitárias Recife, conversamos com os dirigentes da ABRACO - Recife (Associação Brasileira de Rádios

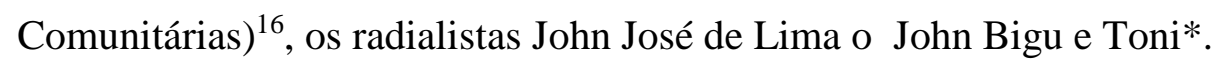

\footnotetext{
${ }^{15} \mathrm{Na}$ ocasião 110 policiais federais participaram de operações de apreensão em duas etapas (em março e outubro de 2008), agindo em uma série de cidades na Região do Recife e do seu entorno na tentativa de cumprir 90 mandados de busca e apreensão expedidos pela justiça federal.

${ }^{16}$ A ABRAÇO (Associação Associação de Rádio Comunitárias) fundada em 25 de agosto de 1996 com sede na cidade de Brasília-DF, de acordo com o seu estatuto "é uma entidade com missão sociocultural e comunicacional (...) visando contribuir para um melhor conhecimento da realidade e objetivando o desenvolvimento geral da sociedade brasileira, sob os aspectos socioeducacionais e artístico-culturais" (Estatuto da ABRAÇO Nacional, Artigo $2^{\circ}$ ). Em Recife o trabalho associativo das rádios comunitárias se iniciou com a Associação Recifense de Rádios Comunitárias (ARRCS) sediada na Boa Vista no início dos anos 2000. Hoje, além da ABRAÇO-PE, os
} 
Ainda sem uma sede fixa, Toni e John Bigu explicam* que a ABRACO, na prática, começou as suas ações na Região do Recife apenas no ano de 2010, resultado de gestões anteriores pouco operantes, como a exercida por Napoleão Assumpção. A associação conta com 40 emissoras de toda a Região do Recife, porém tem sofrido para ampliar a sua rede de contatos, visto que, em muitas emissoras as pessoas têm medo de lhes fornecerem quaisquer informações, relata John Bigu*: "vão descobrir que estou aqui e vão me fechar (...) a gente tem que começar a trabalhar e mostrar serviço e eles vão saindo da toca devagarinho."

Resultado da desconfiança dos agentes das emissoras não-concessionadas inexiste mesmo entre os dirigentes da ABRACO-Recife um levantamento preciso de quantas delas operam na Região do Recife. Estimativas dão conta de que em Recife existiriam 50 emissoras não concessionadas em operação, enquanto Olinda abrigaria 20 delas, a imensa maioria nas periferias da cidade.

Aspectos necessários para o trabalho de uma rádio comunitária são o respeito à diversidade do lugar, a postura laica e a criação de uma comunicação genuína com o entorno: "Uma rádio comercial tem um locutor e uma rádio comunitária tem um comunicador" propõe Toni*. O militante que cuida de uma emissora não concessionada no litoral sul de Pernambuco e participou de ações em diversas rádios livres por todo o interior do estado ${ }^{17}$, conta* que é comum nesses lugares a difusão de um jornalismo feito pelos próprios moradores, responsáveis por reportar os fatos de seu cotidiano.

Por sua vez Bigu é locutor de uma emissora comunitária em Rio Doce, Olinda, a Rádio Sol, sediada por motivos de segurança em sua própria casa. A Rádio Sol atinge os bairros do norte de Olinda: Casa Caiada, Maranguape e Jardim Atlântico, além do centro de Paulista, mas nessa última área com faixas sombrias, de baixa definição.

Segundo John Bigu*, lhe preocupa não somente o conteúdo musical veiculado nas rádios, mas a informação em geral difundida. Desse modo, o dirigente propõe um esforço no sentido de implementar uma programação diretamente relacionada com as demandas do entorno, algo que não se encontra entre as rádios concessionadas.

militantes das rádios livres em Recife e em Pernambuco se organizam por meio da Federação de Rádios Comunitárias de Pernambuco (Fercom-PE) e pela Associação de Rádios Comunitárias Pernambucanas (Sede na Rua do Hospício 33, Boa Vista) contando com o apoio ainda de órgãos como o Fórum Pernambucano de Comunicação.

17 Sobre os sistemas técnicos utilizados nas emissoras livres, quando indagados a respeito da utilização da tecnologia do link, onde a torre é desmembrada da emissora, os dirigentes* explicaram que a prática não é utilizada na Região do Recife, sendo mais comum no interior de Pernambuco. 
No que se refere a estrutura de um rádio livre, estima-se que para montar uma emissora completa seja necessário empenhar cerca de $\mathrm{R} \$ 7.000,00$, porém a maioria das emissoras são montadas pouco a pouco. Sobre a evolução da estrutura de sua emissora, John Bigu* afirma ter começado a trabalhar com uma série de improvisações: tratamento acústico com tapumes e caixas de ovo, microfones deteriorados, computador com baixa capacidade, entre outros. Com o tempo investiu em sua estrutura, e como boa parte das emissoras não concessionadas da Região do Recife, conta hoje com todo um equipamento reserva para ser acionado em caso de apreensão.

Além do tratamento acústico, grosso modo os equipamentos necessários à instalação de uma emissora de rádio são: o transmissor com um gerador de som estéreo, filtro de ondas, que com o frete custa em torno de $\mathrm{R} \$ 2.00,00$, uma antena que custa em torno de $\mathrm{R} \$ 500,00$, além de microfones, mesa de som e um computador.

Uma das precauções ao se instalar uma emissora é o estudo para ocupar uma frequência vaga, e com uma determinada potência que não cause interferência em outras emissoras. Nesse processo de escolha, de nada valem os cálculos e teorias de radiodifusão, é necessário experimentar as possibilidades, se deslocar pelo entorno, saber das frequências ocupadas e dos canais livres. John Bigu* conta como realizou o procedimento para instalação de sua emissora: "estudei, andei várias vezes com o carro e vi que aquela frequência tava livre no meu município (Olinda). Vi que nessa frequência havia apenas na Bomba do Hemetério (Recife) uma rádio." Trata-se de um circuito que prescinde de regulação externa funcionando a partir do bom senso de seus próprios agentes.

Nas rádios comunitárias e não concessionadas os anúncios de publicidade raramente são elaborados fora dos estúdios das emissoras. Aspectos dos circuitos inferiores da economia, trata-se de chamadas para o comércio local: sapateiros, padarias, mercados, oficinas, entre outros, se utilizam desse meio para divulgar seus produtos e serviços. Interessante destacar que em algumas emissoras não concessionadas tenta-se elaborar peças publicitárias num tempo de trinta segundos, semelhante a padronização adotada nas rádios comerciais concessionadas. Em outras rádios esse tempo padrão não é adotado e o anúncio pode variar de 25 a 45 segundos.

De acordo com Bigu*, em sua emissora, cada comerciante paga o que pode, de R\$ 15,00 a R \$ 30,00 por semana de propaganda, elaborada de modo caseiro com uma pequena estrutura atingindo um bom resultado: “Com um computadorzinho, um microfone bom, uma 
mesinha, você vai lá e grava com a qualidade de uma rádio comunitária e os comerciantes geralmente ficam satisfeitos"

Por meio da Rádio Sol, são organizadas festas em Rio Doce, bem como ações sociais das mais diversas: exames médicos, aferições de pressão arterial, entre outros. Toma-se cuidado para evitar bailes com bandas de brega, que segundo John e Toni, invariavelmente terminam em brigas, além disso, evita-se tocar certas músicas na emissora, um processo de difícil negociação e por vezes envolto em contradições:

Não incomodo a comunidade, não toco música escrota na comunidade, têm umas ou outras que passam, por que a turma fica ouvindo essas rádios... Que são financiadas pelos poderes públicos e tocam esse tipo de música e enchem a cabeça das pessoas e as pessoas ficam pedindo: eu quero tal música, tal música...

Quando uma música fora de seu arquivo é pedida pelos moradores durante a programação, John* explica que pede um tempo necessário para baixar a música da internet e diz ao vivo: "vou buscar na feira de Peixinhos (divisa de Olinda e Recife), o motoboy já vai trazer..." Em outros momentos ele pede ao vivo uma refeição e logo recebe de um morador, um bolo, um café. De acordo com John* não é possível viver apenas com a receita da emissora, desse modo ele trabalha ainda como DJ e elaborador de sítios na internet. O locutor afirma* ter desistido de legalizar a sua emissora devido ao excesso de burocracia e empecilhos em torno do processo.

\section{CONSIDERAÇÕES FINAIS}

Abordar a radiodifusão, como parte da análise do da metrópole do Recife, permite-nos refletir sobre a circulação de informações no território a partir do componente sonoro e musical. Revelam-se por meio da radiodifusão, as associações entre os grandes grupos de informação e densidades técnico-informacional-normativas. $\mathrm{O}$ exame do circuito das rádios concessionadas na Região do Recife evidencia o controle de grupos políticos e/ou religiosos ligados à difusão de informações.

Aclaram-se ainda os conflitos entre tais agentes verticalizantes, para quem o território se apresenta como recurso e agentes abrigados no cotidiano da metrópole, difusores de espessuras ascendentes, atuantes, sobretudo, por meio das rádios livres e/ou comunitárias.

Assim sendo, vê-se o desvelamento da densidade comunicacional, esta de modo diverso às densidades técnica e informacional, pois mais arraigada ao lugar, ao cotidiano, ao 
saber e à produção de informações ascendentes Ter-se-ia na densidade comunicacional um elemento de transformação, pois revelador de "interesses comuns que podem conduzir a uma consciência política.” (Santos \& Silveira, 2001, p. 101).

Trata-se de uma agenda de pesquisa aberta, quiçá condutora a elementos para se pensar novos usos do território pautados na produção de informações fundadas nos lugares e em seus sujeitos.

\section{Referências bibliográficas}

ADORNO, T. W. Indústria cultural e sociedade. São Paulo: Paz e Terra, 2004 [1947].

ANDRIOTTI, C. D. O movimento das rádios livres e comunitárias e a democratização dos meios de comunicação no Brasil. Dissertação de mestrado apresentada ao Departamento de Ciências Sociais do Instituto de Filosofia e Ciências Humanas da Unicamp. Campinas-SP, 2004.

HAGERSTRAND, T. The propagation of innovation waves. Lund Studies in Geography, n 4, 1952. Pp. 1-21.

HÄGERSTRAND, T. Innovation diffusion as a spatial process. Chicago/London: The University of Chicago Press, 1967.

RIBEIRO, A. C. T. Pequena reflexão sobre categorias da teoria crítica do espaço: território usado, território praticado. In SOUZA, Maria Adélia de. (et al). Território Brasileiro: usos e abusos. Campinas: Edições Territorial, 2003. Pp. 29-40.

SANTOS, M. e SILVEIRA, M. L. O Brasil: território e sociedade no início do século XXI. Rio de Janeiro: Record, 2001.

SANTOS, M. A revolução tecnológica e o território: realidades e perspectivas. Caderno Prudentino de Geografia. n 13, 1991. Pp. 141-152.

Técnica, espaço e tempo. São Paulo-SP: Hucitec, 1994.

Hucitec, 1997.

A natureza do espaço: técnica e tempo, razão e emoção. São Paulo:

O território e o saber local: algumas categorias de análise In Cadernos IPPUR, ano XIII, $\mathrm{n}^{\circ}$ 2, 1999. Pp. 15-26.

SANTOS, M. et al. O papel ativo da geografia, um manifesto. Texto apresentado no XII Encontro Nacional de Geógrafos. Florianópolis, 2000. 13 páginas.

SCHAFER. R. M. A afinação do mundo - uma exploração pioneira pela história passada e pelo atual estado do mais negligenciado aspecto do nosso ambiente: a paisagem sonora. São Paulo: Unesp, 1997 [1977].

SILVA, A. B. As grandes cidades e o período popular da história: contribuições ao debate. Texto apresentado no III Encontro com o Pensamento de Milton Santos: UFBA, Salvador, 3 e 4 de maio de 2005.

SILVA, C. A. Economia política do território: desafios para pensar a metrópole. In Território e ação social: sentidos da apropriação urbana. SILVA, Catia Antonia da. Rio de Janeiro: Faperj/Lamparina, 2011. Pp. 151-171.

SILVEIRA, M. L.. Economia Política e ordem espacial: circuitos da economia urbana. In Território e ação social: sentidos da apropriação urbana. SILVA, Catia Antonia da. Rio de Janeiro: Faperj/Lamparina, 2011. Pp. 35-51. 
TELES, J. Do frevo ao manguebeat. Recife: Editora 34, 2000.

Recebido em 14 de março de 2017.

Aceito em 02 de outubro de 2017. 